\section{RESULTS OF NORWOOD'S OPERATION FOR LESIONS OTHER THAN HYPOPLASTIC LEFT HEART SYNDROME}

Norwood's operation provides satisfactory palliation for neonates with hypoplastic left heart syndrome. The dominant physiologic features of hypoplastic left heart syndrome, ductal dependency of the systemic circulation and parallel pulmonary and systemic circulations, are shared by a multitude of other less common congenital heart malformations. Theoretically, these should be equally amenable to palliation by Norwood's operation. Between January 1990 and June 1994, 60 neonates with malformations other than hypoplastic left heart syndrome underwent initial surgical palliation by Norwood's procedure. Diagnoses included single left ventricle with levo-transposition of the great arteries (12); critical aortic stenosis (8); complex double-outlet right ventricle (8); interrupted aortic arch with ventricular septal defect and subaortic stenosis (7); ventricular septal defect, subaortic stenosis, and coarctation of the aorta (7); aortic atresia with large ventricular septal defect (6); tricuspid atresia with transposition of the great arteries (6); heterotaxy syndrome with subaortic obstruction (3); and other (3). There were 10 hospital deaths and 50 survivors (83\% survival). After the introduction of inspired carbon dioxide therapy into the postoperative management protocol (1991), 42 of 47 patients survived (89\% survival). Mortality was independent of diagnosis and essentially the same as that for hypoplastic left heart syndrome. With minor technical modifications, Norwood's operation provides satisfactory initial palliation for a wide variety of malformations characterized by ductal dependency of the systemic circulation in anticipation of either a Fontan procedure or a biventricular repair. (J THORAC CARDIOVASC SURG 1995;110:1555-62)

Marshall L. Jacobs, $\mathrm{MD}^{\mathrm{a}}$ (by invitation), Jack Rychik, $\mathrm{MD}^{\mathrm{b}}$ (by invitation), John D. Murphy, $\mathrm{MD}^{\mathrm{b}}$ (by invitation), Susan C. Nicolson, $\mathrm{MD}^{\mathrm{c}}$ (by invitation), James $\mathrm{M}$. Steven, $\mathrm{MD}^{\mathrm{c}}$ (by invitation), and William I. Norwood, MD, PhD, ${ }^{a}$ Philadelphia, Pa.
$\mathrm{H}^{\mathrm{n}}$ ypoplastic left heart syndrome is characterized anatornically by atresia or extreme stenosis of the aortic valve and marked hypoplasia or virtual absence of the left ventricle. The principal physiologic consequence of this anatomy is that systemic blood flow is provided largely or entirely from the right ventricle through the ductus arteriosus. The

From the Divisions of Cardiothoracic Surgery, ${ }^{a}$ Cardiology, ${ }^{b}$ and Cardiac Anesthesia, ${ }^{c}$ The Children's Hospital of Philadelphia, Philadelphia, Pa.

Read at the Seventy-fifth Annual Meeting of The American Association for Thoracic Surgery, Boston, Mass., April 23-26, 1995.

Address for reprints: Marshall L. Jacobs, MD, Division of Cardiothoracic Surgery, The Children's Hospital of Philadelphia, 34th St. \& Civic Center Blvd., Philadelphia, PA 19104.

Copyright (c) 1995 by Mosby-Year Book, Inc.

$0022-5223 / 95 \$ 5.00+0 \quad \mathbf{1 2 / 6 / 6 7 7 4 1}$ operation devised by Norwood to provide initial surgical palliation for neonates with hypoplastic left heart syndrome embodies three basic principles: (1) the aorta must be associated directly with the right ventricle in a fashion that guarantees unobstructed flow from the right ventricle to the systemic circulation with growth potential obviating further aortic operations, (2) pulmonary blood flow must be regulated for proper growth and development and maturation of the pulmonary vasculature to avoid the development of pulmonary vascular obstructive disease and to minimize the volume load on the ventricle, and (3) a large interatrial communication is created to ensure unobstructed pulmonary venous return and avoid pulmonary venous hypertension.

The application of the now standardized surgical technique to hypoplastic left heart syndrome has provided satisfactory initial surgical therapy for in- 
Table I. Classification of the 60 patients by anatomic diagnosis

\begin{tabular}{lc}
\multicolumn{1}{c}{ Diagnosis } & $n$ \\
\hline Single LV, TGA $\{$ S,L,L\} & 12 \\
Critical aortic stenosis & 8 \\
Complex DORV & 8 \\
IAA with VSD, subaortic stenosis & 7 \\
VSD, subaortic stenosis, coarctation & 7 \\
Aortic atresia, malalignment VSD & 6 \\
Tricuspid atresia, TGA & 6 \\
Heterotaxy syndrome, subaortic obstruction & 3 \\
Other & 3
\end{tabular}

$L V$, Left ventricle; $T G A$, transposition of the great arteries; DORV, double-outlet right ventricle; $L A A$, interrupted aortic arch; $V S D$, ventricular septal defect.

creasingly large numbers of neonates with this malformation. ${ }^{1}$ After the initial palliative operation, the single ventricle continues to provide both systemic and pulmonary blood flow, with these two parallel circulations connected at the arterial level. Better understanding of the critical nature of the ratio of the pulmonary and systemic vascular resistances and the impact of this balance on early postoperative hemodynamics has led to strategies associated with markedly diminished rates of mortality for the Norwood operation. ${ }^{2,3}$ Today, multiple centers that deal with large volumes of cases of congenital heart disease report hospital survival in the range of $80 \%$ to $90 \%$ for initial surgical palliation of hypoplastic left heart syndrome. ${ }^{4-6}$ Subsequent steps in the staged reconstructive surgery lead ultimately to a modified Fontan operation, ${ }^{7}$ achieving normal systemic arterial oxygen saturation and normal volume work for the ventricle.

Although hypoplastic left heart syndrome is the most common form of congenital heart disease with only one fully developed ventricle, a variety of other malformations share the important physiologic features of aortic outflow obstruction and ductal dependency of the systemic circulation. Some, such as single left ventricle with levo-transposition of the great arteries (single ventricle $\{\mathrm{S}, \mathrm{L}, \mathrm{L}\}$, double inlet left ventricle) and tricuspid atresia with dextrotransposition of the great arteries $\{\mathrm{S}, \mathrm{D}, \mathrm{D}\}$, present in the newborn period with a physiologic and anatomic circumstance fundamentally similar to hypoplastic left heart syndrome: a single ventricle providing unobstructed flow into a large well-developed pulmonary artery and ductal dependency of the systemic circulation in the setting of varying degrees of aortic outlet obstruction and accompanying aortic arch hypoplasia or obstruction. The principal ana- tomic differences between these malformations and hypoplastic left heart syndrome are (1) the presence of a single well-developed left ventricle rather than right ventricle and (2) variations from the usual $\{\mathrm{S}, \mathrm{D}, \mathrm{S}\}$ or normal relationship of the great arteries at the base of the heart. A variety of other malformations share the dominant features of aortic outlet obstruction and ductal dependency of the systemic circulation despite the presence of two well-developed ventricles. It seems logical that neonates with cardiac malformations other than hypoplastic left heart syndrome that present with the same abnormal physiologic conditions should be treatable by a similar or identical palliative surgical approach. In this report, we review our institutional experience with Norwood's first-stage palliative operation applied to neonates with lesions other than hypoplastic left heart syndrome.

\section{Patients and methods}

The cardiac surgical database of The Children's Hospital of Philadelphia was reviewed to identify all neonates and infants who had undergone Norwood's first-stage palliative procedure for lesions other than hypoplastic left heart syndrome between January 1990 and June 1994. For purposes of this study, the hypoplastic left heart syndrome population was excluded from the analysis. Hypoplastic left heart syndrome was defined as normally related great arteries with typical aortic atresia and mitral atresia or with severe aortic stenosis, mitral valve hypoplasia, and left ventricular hypoplasia. Also excluded were cases with either double-outlet right ventricle with aortic valve atresia and left ventricular hypoplasia or complete common atrioventricular canal defect malaligned over the right ventricle with associated left ventricular hypoplasia and aortic valve atresia or hypoplasia, which are generally considered to be subsets of hypoplastic left heart syndrome. ${ }^{8}$ Sixty neonates were identified who had undergone Norwood's stage I palliative procedure in whom the diagnoses were distinctly different from hypoplastic left heart syndrome. Anatomic diagnoses are listed in Table I. In 21 patients, the anatomic diagnosis was characterized by the presence of a single ventricle of either right or left ventricular morphology. In the remaining 39 patients, there were either two well-developed ventricles with severe subaortic obstruction (or aortic atresia) and aortic arch obstruction, or two ventricles of which one was underdeveloped in the setting of either straddling, malaligned, or atretic atrioventricular connection. In each instance, two-dimensional echocardiography with Doppler flow analysis revealed right-to-left shunting through the ductus arteriosus and ductal dependency of the systemic circulation. Patient ages ranged from 1 day to 68 days, and patient weights ranged from $1.8 \mathrm{~kg}$ to $4.4 \mathrm{~kg}$.

Details of operation. After echocardiographic evaluation of the anatomy, medical stabilization based on ensur- 

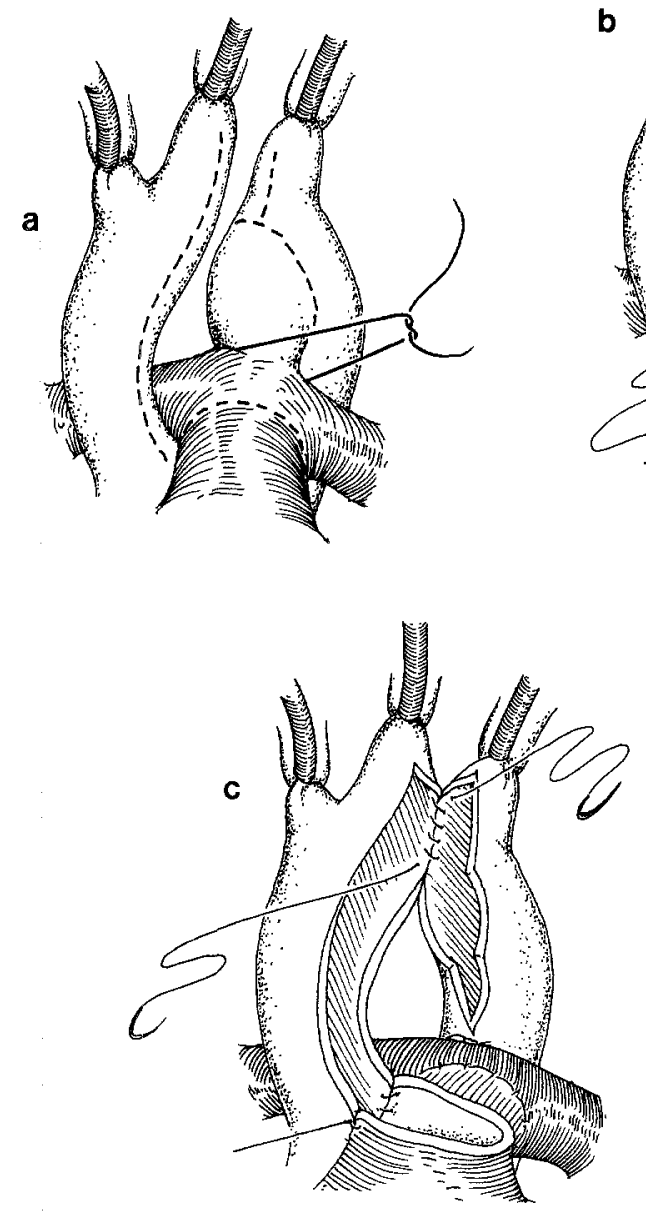
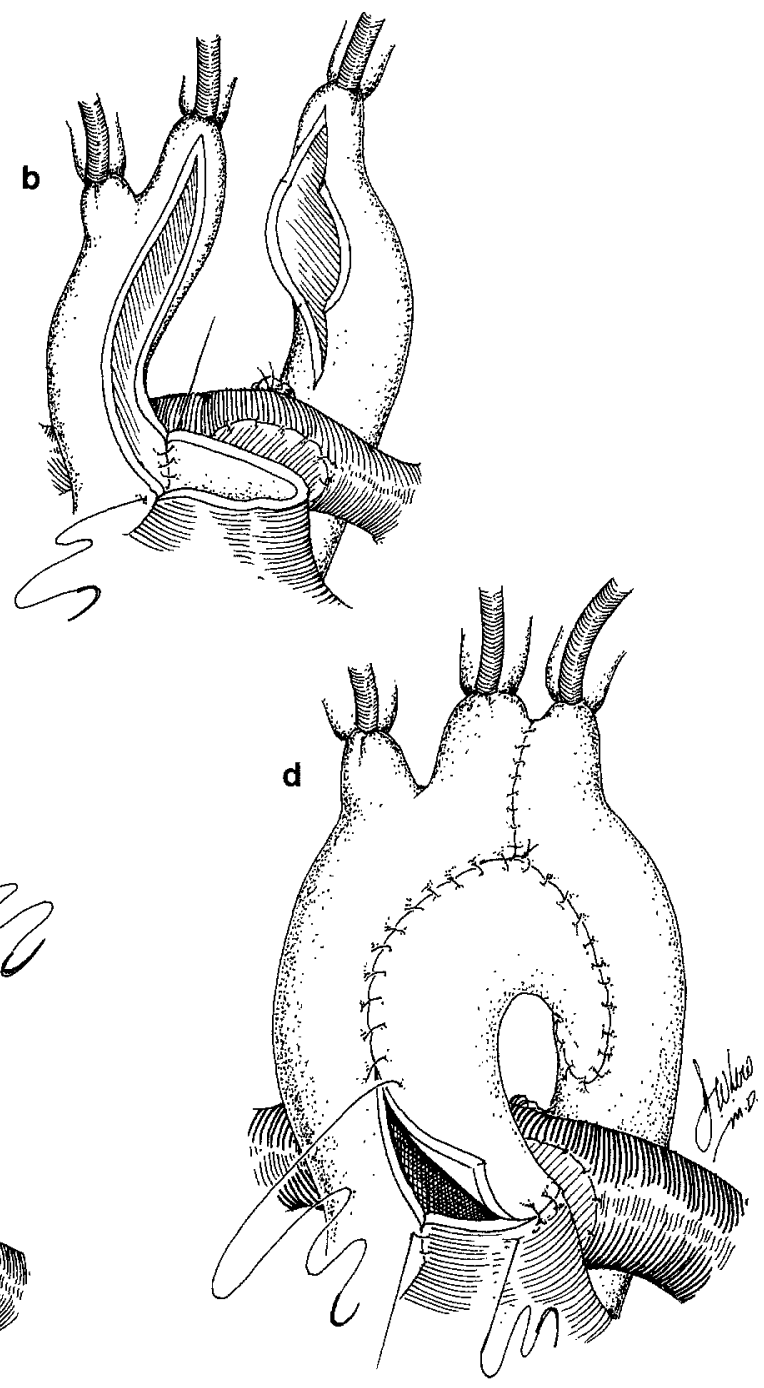

Fig. 1. Operative technique for interrupted aortic arch with ventricular septal defect and severe subaortic stenosis. a, Ligation of ductus arteriosus and lines of incision in ascending and descending aortic segments. b, Proximal portion of divided main pulmonary artery is anastomosed in side-to-side fashion to ascending aorta. c, Aortic arch branches are anastomosed in side-to-side fashion. d, Arch reconstruction is completed by augmentation with gusset of cryopreserved pulmonary artery homograft. (Systemic-to-pulmonary artery shunt is not shown in this illustration.)

ing patency of the ductus arteriosus with prostaglandin infusion was achieved. Ventilatory support was provided as needed to ensure a ratio of pulmonary-to-systemic blood flow (Qp:Qs) as close to 1:1 as could be achieved. Norwood's stage I palliative procedure was then done as previously described. ${ }^{9}$ Basically, after median sternotomy, cardiopulmonary bypass was established with venous drainage via the right atrium and systemic perfusion by means of cannulation of the proximal main pulmonary artery with temporary tourniquet occlusion of the branch pulmonary arteries. During hypothermic circulatory arrest septum primum was excised, the main pulmonary artery transected proximal to the branch pulmonary arteries, and the distal main pulmonary artery closed with a patch of cryopreserved homograft. The ductus arteriosus was ligated at the pulmonary end and transected at its entrance into the thoracic aorta. This opening was extended for more than a centimeter distally on the medial aspect of the descending thoracic aorta and then proximally along the underside of the aortic arch and down the ascending aorta to a point adjacent to the transected proximal main pulmonary artery. Partial side-to-side anastomosis of the transected proximal main pulmonary artery and the ascending aorta was accomplished and the entire aortic arch complex was augmented with a gusset of cryopreserved pulmonary artery homograft. Pulmonary blood flow was provided by means of a polytetrafluoroethylene shunt $(3.5$ $\mathrm{mm}$ or $4 \mathrm{~mm}$ ) interposed between the innominate artery 


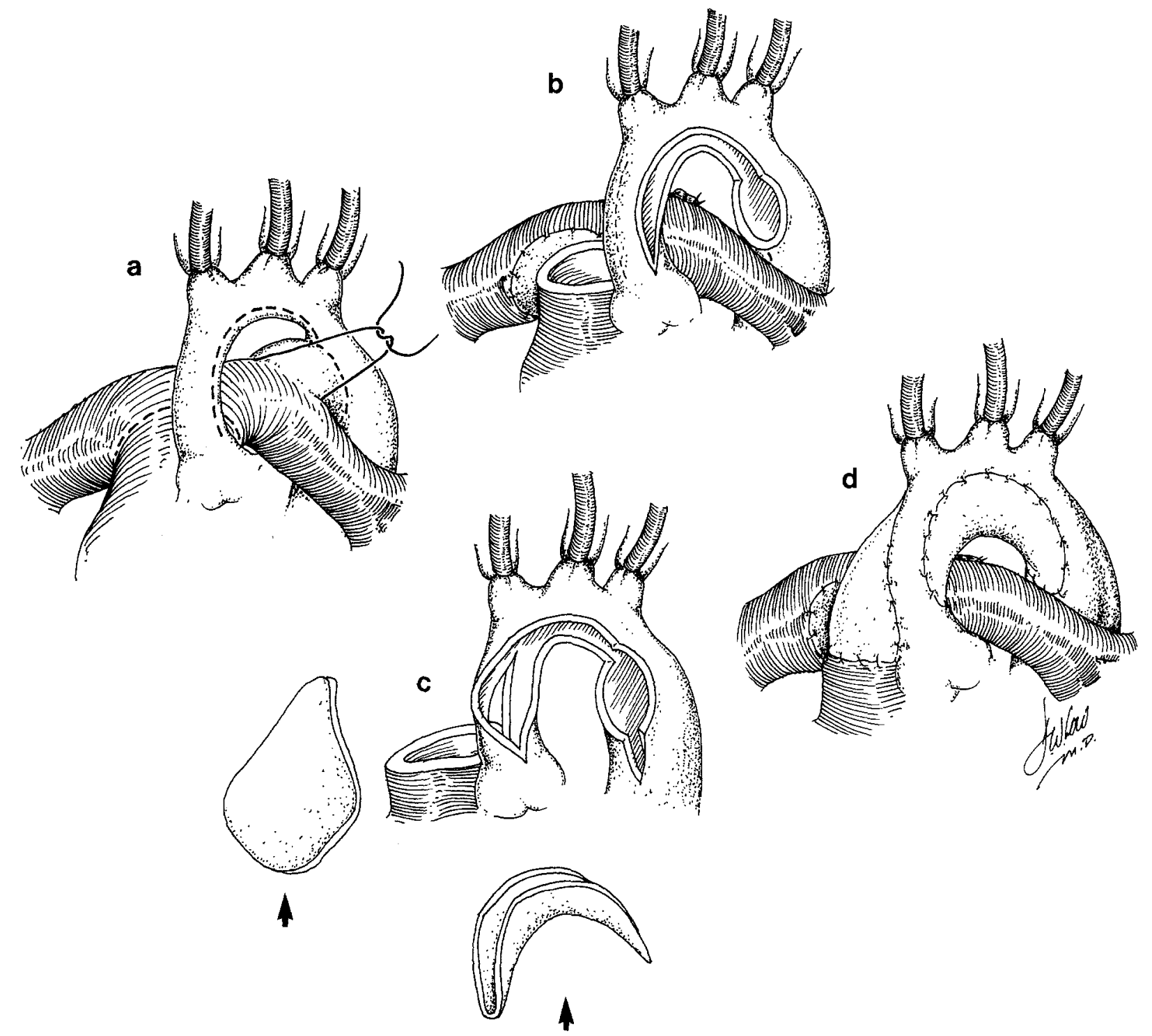

Fig. 2. Operative technique for abnormally related great arteries. This example depicts single left ventricle with transposition of great arteries $\{S, L, L\}$. a, Ligation of ductus arteriosus and lines of incision. $\mathbf{b}$, Pulmonary artery confluence is closed with patch. c, Overlapping incisions in ascending aorta and aortic arch. Augmentation of arch and pulmonary artery-to-aorta anastomosis are accomplished with two separate patches of pulmonary artery homograft (arrows). d, Completed reconstruction. (Systemic-topulmonary artery shunt is not shown in this illustration.)

and the right pulmonary artery or between the underside of the reconstructed aorta and the confluence of the pulmonary arteries.

For certain anatomic diagnoses, the operative procedure was modified slightly. When there was interruption of the aortic arch, the most distal aortic arch branch associated with the ascending aorta and the first branch associated with the descending thoracic aorta were anastomosed in side-to-side fashion and then the entire arch was augmented as usual with a gusset of cryopreserved pulmonary artery homograft (Fig. 1). In some instances of abnormal relation of the great arteries, as for example with transposition of the great arteries $\{$ S,L,L, , the arch reconstruction was accomplished with two separate patches of pulmonary artery homograft rather than one (Fig. 2).

Postoperative management. After the patient was rewarmed to $37^{\circ} \mathrm{C}$ and separated from cardiopulmonary bypass, intravascular volume was maintained by administration of type-specific fresh whole blood (less than 48 hours old). Sternal closure was routinely accomplished and inotropic drugs were used selectively and rarely. 
Ventilatory management was directed to achieve arterial blood gas values reflective of a Qp:Qs close to 1:1. Since May 1991, this strategy has been accomplished by the maintenance of generous minute ventilation (20 to 30 $\mathrm{ml} / \mathrm{kg}$ per breath $\times 20$ breaths $/ \mathrm{min})$ and with the addition of $1 \%$ to $3 \%$ ( 7 to 21 torr) carbon dioxide to the inspired gas mixture. ${ }^{10}$ This has facilitated control of the ratio of pulmonary resistance to systemic resistance and thus of Qp:Qs. Extubation of the trachea was accomplished as soon as the hemodynamic condition was stable and the patient was fully awake, usually within 24 to 48 hours after operation. Digoxin and furosemide (Lasix) were routinely administered and nutritional support was maximized with a combination of intravenous and enteral feeds.

Statistical analysis. The relationship between hospital mortality and anatomic diagnosis group was assessed by $\chi^{2}$ analysis of contingency tables. ${ }^{11}$

\section{Results}

Survival, All patients survived the operation. There were 10 hospital deaths and 50 patients were discharged home alive in satisfactory condition (hospital survival 83\%). Since May 1991, when postoperative management that routinely included a strategy based on addition of carbon dioxide to the inspired gases was instituted, there have been 5 deaths and 42 survivors (hospital survival $89 \%$ ). Contemporaneous hospital survival for hypoplastic left heart syndrome was 91\% (1994, 29 hospital survivors among 32 patients who underwent operation). Hospital survival by anatomic diagnosis is shown in Table II. There was no relationship between anatomic diagnosis and hospital survival, nor was there a relationship between outcome and univentricular or biventricular morphology. There have been two late deaths after palliation: one instance of sudden death at home approximately $1 \frac{1}{2}$ months after operation and one death at 7 months after operation in the setting of a respiratory infection.

Hemodynamic evaluation. All survivors have been subjected to hemodynamic evaluation by means of echocardiography and cardiac catheterization at 5 to 12 months after initial surgical palliation in anticipation of either a staged Fontan procedure or a biventricular repair. Three patients had evidence at catheterization of residual or recurrent distal aortic arch obstruction, which was relieved by balloon dilation. Hemodynamic data for the entire patient group expressed as mean values and standard deviation were as follows: aortic saturation $79 \%(6 \%)$, Qp:Qs $1.4(0.6)$, and ventricular enddiastolic pressure $9 \mathrm{~mm} \mathrm{Hg}$ (3 $\mathrm{mm} \mathrm{Hg}$ ). Mild neoaortic valve insufficiency was noted in six patients. No patients had moderate or severe neoaor-
Table II. Early outcome of Norwood's operation by anatomic diagnosis

\begin{tabular}{|c|c|c|c|}
\hline Diagnosis & $n$ & Deaths & $\begin{array}{c}\text { Hospital } \\
\text { survival } \\
(\%)\end{array}$ \\
\hline Single LV, TGA $\{S, L, L\}$ & 12 & 3 & 75 \\
\hline Critical aortic stenosis & 8 & 1 & 88 \\
\hline Complex DORV & 8 & 1 & 88 \\
\hline IAA with VSD, subaortic stenosis & 7 & 1 & 86 \\
\hline VSD, subaortic stenosis, coarctation & 7 & 0 & 100 \\
\hline Aortic atresia, malalignment VSD & 6 & 2 & 67 \\
\hline Tricuspid atresia, TGA & 6 & 2 & 67 \\
\hline Heterotaxy, subaortic stenosis & 3 & 0 & 100 \\
\hline Other & 3 & 0 & 100 \\
\hline
\end{tabular}

$p=0.66$; statistical analysis by $\chi^{2}$ analysis of contingency tables ${ }^{11}$; see text. $L V$, Left ventricle; $T G A$, transposition of the great arteries; $D O R V$, double-outlet right ventricle; $L A A$, interrupted aortic arch; $V S D$, ventricular septal defect.

tic valve insufficiency. All patients were judged to have hemodynamics suitable for either staged Fontan reconstruction or biventricular repair.

\section{Discussion}

Norwood's first-stage operation for hypoplastic left heart syndrome provides satisfactory initial palliation for infants with the most common congenital heart malformation characterized by the presence of a single ventricle. That multiple centers report contemporary results in the range of $75 \%$ to $90 \%$ hospital survival with this procedure is evidence of the sound physiologic basis of this technical exercise. It is a logical extension of the principles of this palliative strategy that the procedure can be applied to the wide variety of other less common cardiac malformations that share the anatomic features of aortic outflow obstruction and aortic arch obstruction and the physiologic condition of ductal-dependent systemic circulation. In 1991 Rychik and associates $^{12}$ reported the results of Norwood's earlier experience with application of the stage I procedure to lesions other than hypoplastic left heart syndrome with hospital survival of $68 \%$, which was comparable to the early survival for hypoplastic left heart syndrome reported in 1988 by Pigott and associates. ${ }^{13}$ Greater understanding of factors that influence the delicate balance of pulmonary and systemic flow in the early postoperative period has led to more precise control over the postoperative hemodynamics and thus a more satisfactory and predictable outcome. ${ }^{14}$ It is our impression at The Children's Hospital of Philadelphia that the use of carbon dioxide as a drug to influence pulmonary vascular 
resistance in the perioperative period has enhanced our ability to treat neonates after this type of palliative operation. ${ }^{15}$

The trend in hospital survival for this diverse patient group has paralleled that for hypoplastic left heart syndrome as evidenced by the similar outcome for patients in this study compared with the outcome for those with hypoplastic left heart syndrome being treated at the same and other institutions in recent years. Because Norwood's first-stage palliative procedure is, with the exception of atrial septectomy, essentially an extracardiac operation involving reorganization of the great arteries and construction of a systemic-topulmonary artery shunt, it is not surprising that the outcome is not primarily influenced by the intracardiac anatomy. Minor technical modifications appear to nullify the potential impact of abnormal relation of the great arteries on the outcome of reconstruction. Multiple centers have reported successful application of Norwood's operation to small groups of patients with a variety of heart malformations akin to those described in this report, ${ }^{16-18}$ and Kanter and associates ${ }^{19}$ recently reported excellent intermediate results with a group of 18 such patients. This report, then, supplements an increasingly large and widespread experience supporting the applicability of Norwood's first-stage palliative procedure to a variety of complex cardiac malformations, many of which were believed previously to be uniformly lethal or manageable only by heart replacement. Assessment of the durability of the Fontan-type circulation and of the extent to which efforts should for some patients be directed at an eventual biventricular repair awaits further follow-up and later analysis of this and other groups of patients treated by similar strategies.

\section{REFERENCES}

1. Norwood WI Jr. Hypoplastic left heart syndrome. Ann Thorac Surg 1991;52:688-95.

2. Jobes DR, Nicolson SC, Steven JM, Miller M, Jacobs ML, Norwood WI. Carbon dioxide prevents pulmonary overcirculation in hypoplastic left heart syndrome. Ann Thorac Surg 1992;54:150-1.

3. Mosca RS, Bove EL, Crowley D, Satinder KS, Schork MA, Kulik TJ. Postoperative hemodynamics in babies following the "Norwood" operation. Circulation 1994; 90(Suppl):I204.

4. Iannettoni MD, Bove EL, Mosca RS, et al. Improving results with first-stage palliation for hypoplastic left heart syndrome. J Thorac Cardiovasc Surg 1994; 107:934-40.

5. Starnes VA, Griffin ML, Pitlick PT, et al. Current approach to hypoplastic left heart syndrome. J THORAC CARdiovasc Surg 1992;104:189-95.

6. Weldner PW, Myers JL, Gleason MM, et al. The Norwood operation and subsequent Fontan operation in infants with complex congenital heart disease. J Thorac Cardiovasc Surg 1995;109:654-62.

7. Norwood WI, Jacobs ML, Murphy JD. Fontan's procedure for hypoplastic left heart syndrome. Ann Thorac Surg 1992;54:150-1.

8. Jacobs ML, Norwood WI, eds. Hypoplastic left heart syndrome. In: Pediatric cardiac surgery: current issues. Boston: Butterworth-Heinemann, 1992; $182-92$.

9. Norwood WI, Lang P, Hansen DD. Physiologic repair of aortic atresia-hypoplastic left heart syndrome. N Engl J Med 1983;308:23-6.

10. Jacobs ML, Murphy JD, Nicolson SC, Steven JM, Norwood WI. Manipulation of inspired carbon dioxide in neonates with one ventricle and systemic-topulmonary artery shunt. Circulation 1991;84(Suppl): II238.

11. Glantz SA. Primer of biostatistics. New York: McGraw Hill, 1992:374.

12. Rychik J, Murdison KA, Chin AJ, Norwood WI. Surgical management of severe aortic outflow obstruction in lesions other than hypoplastic left heart syndrome: use of a pulmonary artery to aorta anastomosis. J Am Coll Cardiol 1991;18:809-16.

13. Pigott JD, Murphy JD, Barber G, Norwood WI. Palliative reconstructive surgery for hypoplastic left heart syndrome. Ann Thorac Surg 1988;45:122-8.

14. Mora GA, Pizarro C, Jacobs ML, Norwood WI. Experimental model of single ventricle: influence of carbon dioxide on pulmonary vascular dynamics. Circulation 1994;90:II43-6.

15. Gullquist S, Schmitz ML, Hannon GD, et al. Carbon dioxide in the inspired gas improves early postoperative survival in neonates with congenital heart disease following stage I palliation (Norwood). Circulation 1992;86(Suppl):I1435.

16. Tchervenkov CI, Beland MJ, Latter DA, Dobell ARC. Norwood operation for univentricular heart with subaortic stenosis in the neonate. Ann Thorac Surg 1990;50:822-5.

17. Imai $Y$, Kurosawa $H$, Fujiwara $T$, et al. Palliative repair of aortic atresia associated with tricuspid atresia and transposition of the great arteries. Ann Thorac Surg 1991;51:646-8.

18. Ilbawi MN, Idriss FS, DeLeon SY, Muster AJ, Benson DW Jr, Paul MH. Surgical management of patients with interrupted aortic arch and severe subaortic stenosis. Ann Thorac Surg 1988;45:174-80.

19. Kanter KR, Miller BE, Cuadrado AG, Vincent RN. Successful application of the Norwood procedure for 
infants without hypoplastic left heart syndrome. Ann Thorac Surg 1995;59:301-4.

\section{Discussion}

Dr. Ivan Rebeyka (Toronto, Ontario, Canada). I would like to commend Dr. Jacobs not only on his presentation but even more so on results that are the envy of many of us.

There has clearly been a change in the results of the Norwood operation and what has been a procedure that could only be done by a select few is now being successfully applied by an increasingly larger number of institutions. The authors must take great pride in knowing that their concepts and methods have had a positive impact on the treatment of infants with congenital heart disease everywhere.

The authors' demonstration of what is possible to achieve has prompted us to carefully study and apply these methods in Toronto. During the past 12 months we have been able to achieve an $80 \%$ first-stage survival in the 19 patients operated on during that time. However, as one's results with the Norwood procedure improve, there is obviously a shift in the relative risk of the performance of this operation in those subsets of patients in whom other forms of surgical treatment are possible. Therefore my first question is this: what criteria in terms of subaortic diameter or anatomy do you use in deciding to opt for the Norwood procedure?

Review of the number of patients in each of the diagnostic subsets reveals that at least one third could potentially have a biventricular repair, and considering that the long-term morbidity and mortality of the Fontan circulation is unknown but, we hope, improving in the current era, have you any experience with subsequent conversion to a biventricular repair?

Finally, I have a practical question. We are able to extubate our patients the morning after operation as is done in Philadelphia and Ann Arbor, but we would like to know whether you try to control the carbon dioxide tension after extubation; if not, why do you think it is not necessary after the initial 12 to 24 hours? I would hazard to guess that once the postoperative ventricular dysfunction is resolved in these patients they have sufficient cardiac output to balance or at least compensate for alterations in Qp:Qs.

Dr. Jacobs. The issue of assessing subaortic obstruction and establishing a threshold for saying that a subaortic region is too small to allow the left ventricle to support the systemic circulation is a critical but difficult one. With regard to this question, we analyzed our results with only those patients with interrupted aortic arch as a group and presented them last year at the American Heart Association, and I will try to summarize them briefly as follows.

In an average term-size baby of approximately $3 \mathrm{~kg}$ or more, it has been our impression, on the basis of earlier experience, that a subaortic region of $3 \mathrm{~mm}$ or less has a likelihood of being too small for the left ventricle to support the systemic circulation after an anatomic repair. Others, like Dr. Bove, have addressed this by enlarging the subaortic region by resection of some muscle. Our experience with that has been less favorable, and I think that the tendency toward that kind of outcome is reflected in the Congenital Heart Surgeons Society study.
I would caution you, however, that when we looked at these patients, we found that echocardiographic measurements of the subaortic region in several views and by several observers were not always constant. Thus what is a $3 \mathrm{~mm}$ subaortic region to one may be to another or in another view a 4 or a 4.5 or a $2.5 \mathrm{~mm}$ subaortic region, which means it is difficult to give a hard and fast answer because it is not possible to make hard and fast measurements. Our experience has suggested to us that when the subaortic region is very small, on the order of about $3 \mathrm{~mm}$, the outcome was more predictable with application of a Norwood type of operation.

That leads me to answers to your second question. Applying the Norwood operation in the neonatal period does not by any means obviate the possibility of a biventricular repair later on. When the subaortic region remains very small or in aortic atresia with ventricular septal defect, for example, the eventual biventricular repair is quite reminiscent of the Rastelli operation, with a baffle placed from the left ventricle to the pulmonary valve anulus to create a systemic outflow tract. In certain of these malformations, aortic atresia with large malalignment ventricular septal defect, for example, this is a straightforward procedure, and pretty uniformly successful results have been reported earlier. I would caution that in other of these malformations, such as interrupted aortic arch with a variety of types of ventricular septal defect, and even in some of the patients with two ventricles with posterior malalignment of the infundibular septum, ventricular septal defect, and coarctation, it is critically important to resect infundibular septum and enlarge the ventricular septal defect as described by Dr. LeCompte for the interventricular-biventricular repair to avoid the creation of subaortic obstruction at the time of biventricular repair.

Finally, with regard to your question about the use of carbon dioxide, fortunately its utility is not limited to the period of time when the patient is receiving ventilation with an endotracheal tube. When these patients with parallel circulations and others with a large volume load or a large Qp:Qs, as from truncus arteriosus, for example, are identified, we treat them preoperatively with use of a hood or a tent to which carbon dioxide is added. In instances such as these when the patients are extubated, which not always but frequently occurs 1 or 2 days after operation, they continue to receive carbon dioxide as a drug in a tent while breathing spontaneously through the natural airway for a period of several additional days. I think you are quite correct that the volume load on the ventricle and the lability of the volume load are much better tolerated 3 or 4 days after the operative procedure and the period of myocardial ischemia than they are in the immediate postoperative interval.

Dr. Christo I. Tchervenkov (Montreal, Quebec, Canada). I congratulate Dr. Jacobs and colleagues in Philadelphia for demonstrating that this operation can be applied to a number of other lesions that are very complex and occur in the neonatal period. Because its application is to such a heterogeneous group of patients, one might be tempted to call it the universal operation.

I am in full agreement with the indications that the authors have included in their series, especially those patients with single ventricle physiology that mimics the hypoplastic left heart syndrome. We have applied this operation 
as early as 1987 to patients with tricuspid atresia, transposed great arteries, and subaortic stenosis, especially at the bulboventricular foramen level. We have also used it for critical aortic stenosis with severe dysfunction of the left ventricle as a salvage operation. However, my feelings differ just slightly as to patients with a biventricular heart who have a ventricular septal defect.

Specifically, I would like to talk about double-outlet right ventricle with severe subaortic stenosis with a subpulmonary ventricular septal defect and interrupted aortic arch with severe subaortic stenosis and a ventricular septal defect. In this situation, we have shown in a previous paper the concept of the Ross-Konno operation. Here is a perfect example of where one can use an in situ pulmonary autograft by directing the ventricular septal defect into the main pulmonary artery.

In this way we achieve left ventricle-to-proximal pulmonary artery continuity. The aortic arch is enlarged in a similar manner to what the authors have described for the Norwood operation, and the systemic circulation can be brought over the proximal main pulmonary artery. Finally, the right ventricle-to-pulmonary artery continuity can be established with a homograft, and a biventricular repair is achieved. In the subset of patients with interrupted aortic arch, this really creates a triple-outlet heart; however, this is a biventricular repair with a single operation.

The question I have for Dr. Jacobs is how many patients in your series may have been a candidate for this approach? Did you consider this approach, and why were these patients excluded? Also, of those patients who had a biventricular heart, how many received a subsequent two-ventricle repair, and did you notice any significant difference in the mortality with a Norwood operation for a two-ventricle heart versus that for a single-ventricle heart?

Dr. Jacobs. Dr. Tchervenkov's substantial and successful efforts at biventricular repair for these challenging hearts in neonates are well recognized.

He has illustrated here essentially what we have come to refer to as a one-stage Norwood operation with a biventricular repair, which says essentially that the organization of the outlet from the heart and the great arteries with anastomosis of the proximal main pulmonary artery to the aorta and augmentation of the arch is identical to what is performed in a stage I operation. The difference is that rather than a systemic-to-pulmonary artery shunt there is an interventricular baffle and some reconstruction of the right ventricular outflow tract, creating continuity between the right ventricle and the branch pulmonary arteries.

We have used this approach selectively in some neonates. As we have become more satisfied with our ability to manage the postoperative physiologic state after the Norwood operation, we have tended more recently to stage such a reconstruction, doing the Norwood operation first and then doing the biventricular repair as a secondstage procedure. There are pluses and minuses to each of these strategies, and I would say that one of the shortcomings of the palliative strategy that we have undertaken is the still somewhat precarious nature of the univentricular-type circulation with a systemic-to-pulmonary artery shunt. Thus even for some patients in whom the heart will ultimately be reconstructable by a biventricular repair, we have chosen at 5 or 6 months to do a bidirectional Glenn or hemi-Fontan operation, which I do not think burns any bridges and which can be taken down at the time of a biventricular repair, but which provides a somewhat more stable physiologic condition than the parallel circulations connected at the arterial level.

Of the 60 patients in this series, 8 have thus far had biventricular repairs. As you intimated, there are a considerably larger number who could ultimately undergo reconstruction in that fashion. Some are awaiting a biventricular repair as a second stage, and some received at 6 months a hemi-Fontan procedure with the option of either completing the Fontan or performing the biventricular repair at a year. We have tended somewhat away from the complete biventricular repair in the neonate because of the potential problems with pulmonary arteryright ventricle conduits in that age group, but obviously your excellent results suggest that this need not be a prohibitive factor.

Dr. Giovanni Stellin (Padoua, Italy). There is a variety of critical aortic stenosis with a normal-size atrioventricular cavity and hypoplastic ascending aorta and arch in which the left ventricle is dysfunctioning perhaps because of the presence of endocardial fibroelastosis or a dysplastic mitral valve. We treat patients with this condition with a Norwood first-stage operation. It is our impression that, because of the presence of a well-developed left ventricular cavity, the outcome of these patients is not as good as it is in those with a very hypoplastic left ventricle. I wonder whether in your experience you have ever encountered such patients and, if so, what your results were with the Norwood operation in this variety of critical aortic stenosis and good-size left ventricular cavity.

Dr. Jacobs. There were seven or eight patients in this series in whom the principal anatomic diagnosis was critical aortic stenosis. Those patients underwent a Norwood operation either because balloon aortic valvotomy failed to improve the condition or because of a prediction that the left ventricle would not function well enough to support the systemic circulation. This is sometimes predicated on the echocardiographic appearance of a very bright, dense endocardium, suggesting endocardial fibroelastosis, and sometimes it is merely predicated on the basis of an akinetic state of the left ventricle.

The outcome for such patients treated by staged reconstruction, beginning with a Norwood procedure, has been no different from that of the rest of the population, but having heard today the excellent results of Ross-Konno reconstructions in similar neonates with critical aortic stenosis in whom the left ventricle is not functioning at the time of evaluation makes one wish that we could figure out those criteria by which we could predict whether the left ventricle, when unobstructed, could support the systemic circulation. So far, on the basis of our inability to predict the recoverability of those poor-looking left ventricles, we have opted for the Norwood operation, but I would be fascinated to know how Dr. Hanley or others try to predict the rehabilitative nature or potential of the left ventricle. 